maintenance analgesic prescriptions, and with <2-years registration before index or matched follow-up start date were excluded. Cox proportional hazard ratios (aHRs) and 95\% confidence intervals $(\mathrm{Cl})$ were calculated to examine the associations adjusted for other covariates. Analyses were stratified according to $\beta$ blocker classes.

Results: Data for 223,436 PS-matched exposed and un-exposed participants were included. $\beta$-blocker prescription associated with a significantly reduced risk of knee OA, knee pain, and hip pain consultations with aHR $(95 \% \mathrm{Cl}) 0.90(0.83-$ $0.98), 0.88(0.83-0.92), 0.85(0.79-0.90)$ respectively. The reduction in hip OA lacked statistical significance $(\mathrm{aHR} 95 \% \mathrm{Cl} 0.94 ; 0.83-1.07)$ (Table 1). On stratified analysis, propranolol and atenolol had a statistically significant protective effect on knee OA and knee pain consultations with aHRs between 0.78 and 0.91 (Figure 1)

Table 1. The association between $\beta$-blocker prescription and incident osteoarthritis and joint pain

\begin{tabular}{lccccc}
\hline Outcomes & Exposed & Events $(\mathrm{n})$ & Person-time & Event rate $(95 \% \mathrm{Cl})^{*}$ & $\mathrm{HR}\left(95 \% \mathrm{Cl}^{11}\right.$ \\
\hline Knee OA & No & 986 & 262,003 & $3.76(3.54-4.01)$ & 1.00 \\
& Yes & 1,101 & 307,231 & $3.58(3.38-3.80)$ & $0.90(0.83-0.98)$ \\
Hip OA & No & 451 & 263,753 & $1.71(1.56-1.87)$ & 1.00 \\
& Yes & 530 & 310,045 & $1.71(1.57-1.86)$ & $0.94(0.83-1.07)$ \\
Knee pain & No & 3,074 & 255,003 & $12.06(11.64-12.49)$ & 1.00 \\
& Yes & 3,560 & 297,027 & $11.99(11.60-12.37)$ & $0.88(0.83-0.92)$ \\
Hip pain & No & 1,767 & 259,515 & $6.81(6.50-7.13)$ & 1.00 \\
& Yes & 1,981 & 304,454 & $6.51(6.23-6.80)$ & $0.85(0.79-0.90)$ \\
& & & & &
\end{tabular}

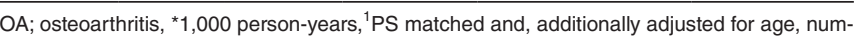
ber of GP consultations, hospital out-patient referrals, hospital admissions in the 12 month period preceding cohort entry, total number of GP consultations for knee or hip injury prior to cohort entry and non-osteoporotic fractures.

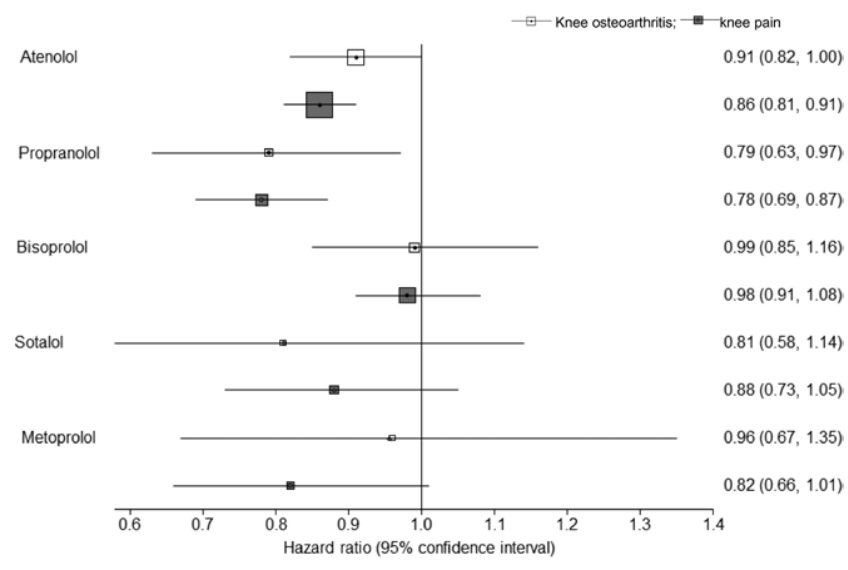

Comparison group is unexposed to $\beta$-blockers; size of the square is proportional to number of events.

Figure 1. The association between individual $\beta$-adrenoreceptor blocking drugs and incident knee osteoarthritis and knee pain ${ }^{11}$ Comparison group is unexposed to $\beta$-blockers; size of the square is proportional to number of events.

Conclusion: $\beta$-blockers appear to reduce consultations for knee OA, and knee or hip pain. Our results imply that, atenolol might be used preferentially for the treatment of people with cardiovascular comorbidities, while, propranolol with its' anti-anxiety effect may be a suitable analgesic in people with $\mathrm{OA}$ and comorbid anxiety.

References:

[1] McAlindon TE, et al. Osteoarthritis and Cartilage 2014;22(3):363-88

[2] Harkanen L, et al. Journal of anesthesia 2015;29(6):934-43. doi: 10.1007/ s00540-015-2041-9

[3] Light KC, et al. The journal of pain 2009;10(5):542-52. doi: 10.1016/j. jpain.2008.12.006

[4] Valdes AM, et al. Arthritis Care Res (Hoboken) 2017;69(7):1076-81. doi: 10.1002/acr.23091

[5] Zhou L,et al. Osteoarthritis and Cartilage 2019 doi: https://doi.org/10.1016/j. joca.2019.08.008

Acknowledgments: This work was funded by the National Institute for Health Research (grant numbers: PB-PG-0816-20025 and NIHR-RP-2014-04-026).

Disclosure of Interests: Georgina Nakafero: None declared, Matthew Grainge: None declared, Ana Valdes Grant/research support from: Pfizer Inc, Consultant of: Consultant for Heel GmBH, Nick Townsend: None declared, Christian Mallen Grant/research support from: My department has received financial grants from BMS for a cardiology trial., Weiya Zhang Consultant of: Grunenthal for advice on gout management, Speakers bureau: Bioiberica as an invited speaker for EULAR 2016 satellite symposium, Michael Doherty Grant/research support from: AstraZeneca funded the Nottingham Sons of Gout study, Consultant of: Advisory borads on gout for Grunenthal and Mallinckrodt, Mamas Mamas: None declared, Abhishek Abhishek Consultant of: Consulting for Inflazome, and Royalties from Uptodate and Springer

DOI: 10.1136/annrheumdis-2020-eular.141

\section{FRI0611-HPR EUROPEAN PRESCRIBERS' PERSPECTIVES ON BIOSIMILARS}

M. Reilly ${ }^{1}$, M. Feldman ${ }^{1} .{ }^{1}$ Alliance for Safe Biologic Medicines, ALEXANDRIA, United States of America

Background: Biosimilars are highly similar, but not identical to originator biologics. In an increasingly resource-constrained environment, switching patients from originator biologics to biosimilars is a growing practice in many jurisdictions. Though automatic substitution of originator biologics with biosimilars is rare in Europe, this practice excludes physicians from decisions regarding the treatment of their patients.

Objectives: As countries seek to control health costs and expand access to biologic therapies, building physician confidence in biosimilars is critical to promoting their use and reaping the cost benefits. This survey will empirically document their perspectives on biologic substitution. These findings may serve as a resource for countries in developing biosimilar policies which build physician confidence in biosimilars.

Methods: The Alliance for Safe Biologic Medicines (ASBM) commissioned 15-minute web-based surveys among biologic prescribers in 6 Western European countries. Respondents must prescribe biologic medicines, must practice in France, Germany, Italy, Spain, Switzerland, or United Kingdom, must specialize in one of 10 practice areas: Dermatology, Endocrinology, Gastroenterology, Hematology Oncology, Immunology, Nephrology, Neurology, Oncology, Ophthalmology, Rheumatology. This survey is a refresh of one conducted in $2013(n=470)$ available at www.safebiologics.org/surveys.

Results: 579 responses were received, 14\% from Rheumatologists $(n=80)$. Biosimilar familiarity was high, increasing from $76 \%$ to $90 \%$ from the 2013 survey; with Rheumatologists the most familiar (99\%). Similarly, the \% of physicians who felt sole treatment decision authority was very important or critical had increased from $72 \%$ to $82 \%$; among Rheumatologists again this figure was higher $(85 \%)$. This pattern was found across many questions, for example the importance of retaining authority to prevent a substitution (a jump from $74 \%$ in 2013 to $84 \%$ in 2019 saying "very important or critical", with Rheumatologists higher than average at $90 \%$ ). Rheumatologists had a higher than average comfort level prescribing biosimilars to new patients, but were the least comfortable with a third party switching their patient for non-medical reasons (e.g. cost): $49 \%$ were "very uncomfortable" compared to an average of $29 \%$ across specialties.

Conclusion: European physicians have increased their familiarity with biosimilars since 2013, with Rheumatologists the practice area with greatest familiarity. After 13 years of experience with biosimilars, Europe's prescribers consider maintaining physician control of treatment decisions to be highly and increasingly important; Remain uncomfortable with switching a patient to a biosimilar for non-medical reasons; Are highly (and increasingly) uncomfortable with a non-medical substitution performed by a third party. When looking specifically at Rheumatologists, these trends are even more pronounced.

Disclosure of Interests: Michael Reilly Grant/research support from: The organization of which I am executive director (ASBM) has received general grants from pharmaceutical companies., Madelaine Feldman: None declared DOI: 10.1136/annrheumdis-2020-eular.3769

FRIDAY, 05 JUNE 2020

HPR Interventions (educational, physical, social and psychological)

\section{FRI0612-HPR EFFECT OF THERMOFORMABLE ORTHOSES ON FOOT FUNCTION IN RHEUMATOID ARTHRITIS PATIENTS: PRELIMINARY RESULTS FROM AN OPEN CLINICAL TRIAL.}

I. Aachari ${ }^{1}$, H. Rkain ${ }^{1,2}$, F. Safaa ${ }^{1}$, L. Benzakour ${ }^{3}$, T. Latifa ${ }^{1}$, N. Alami ${ }^{1}$, R. Guieu ${ }^{4}$, Y. Jammes ${ }^{4}$, N. Hajjaj-Hassouni ${ }^{5}$, F. Allali ${ }^{1} .{ }^{1}$ El Ayachi hospital, Rheumatology, Salé, Morocco; ${ }^{2}$ Faculty of Medicine and Pharmacy, Mohammed V University, Laboratory of Physiology, Rabat, Morocco; ${ }^{3}$ Proteor Group Morocco, Casablanca, Morocco; ${ }^{4}$ UMR MD2 Faculty of Medecine, University AixMarseille, Marseille, France; ${ }^{5}$ International University of Rabat, Rabat, Morocco 
Background: Orthoses and footwear can play an important role in managing foot pathology in patients whose systemic disease is controlled. Foot orthoses are frequently prescribed in clinical practice as an intervention for people with rheumatoid arthritis (RA)

Objectives: The aim of our study is to evaluate the impact of thermoformable orthoses on the functional index of the foot (FFI) in patients with rheumatoid arthritis.

Methods: We conducted an open clinical trial, having consecutively included 14 patients $(85.7 \%$ female, average age $54.8 \pm 10$ years) suffering from rheumatoid arthritis (median progression time of 9 years [5 - 12]). The average DAS28 was $2.7 \pm 1.2$ and the functional impact objectified by the Health Assessment Questionnaire $(\mathrm{HAQ})$ was on average $0.9 \pm 0.7$.

The median deadline from the start of RA and the onset of the foot problem was 3 years $[0-7,75]$. The foot problem was bilateral in $100 \%$ of the cases and inaugural in $85.7 \%$ of the cases.

We evaluated the functional impact of foot injury for all our patients at baseline and 8 weeks after the use of thermoformable orthoses, based on the FFI (Foot function Index) measuring the impact of foot pathology on function in terms of pain, disability and activity limitation.

The comparison of the FFI domains before and after the use of orthoses was carried out using parametric or nonparametric paired tests using The SPSS statistical software.

Results: With the use of foot orthoses, FFI values decreased in all subscales $(p=0,024)$ (pain, disability and activity limitation). This reduction was significant for disability $(0,011)$ but not for pain and activity limitation.

There were no significant correlations between the global FFI and the progression of $R A$, the duration of foot damage and the functional impact measured by the HAQ.

Table 1. The comparison of the FFI domains before and after the use of orthoses.

\begin{tabular}{|c|c|c|c|c|}
\hline & & Before orthoses & After orthoses & $p$-value \\
\hline \multirow{9}{*}{ Pain scale } & When the pain was the worst & $9[5,7-10]$ & $7[4,7-8]$ & 0,09 \\
\hline & Pain in the moming & $4,5[2,2-6]$ & $2[0-3,5]$ & 0,046 \\
\hline & Pain when walking barefoot & $6[4-8]$ & $6,5[3,7-8]$ & 0,719 \\
\hline & Pain when standing barefoot & $6[3,7-7,2]$ & $6[3-7,2]$ & 0,723 \\
\hline & Pain when walking with shoes & $5[2,7-5,2]$ & $3,5[2-5,2]$ & 0,378 \\
\hline & Pain when standing with shoes & $5[2,7-6]$ & $3,5[2-5,2]$ & 0,342 \\
\hline & Pain when walking with orthoses & $0[0-0]$ & $0[0-2]$ & 0,157 \\
\hline & Pain when standing with orthoses & $0[0-0]$ & $0[0-2]$ & 0,317 \\
\hline & Pain at the end of the day & $6[4-8]$ & $3[2-5,2]$ & 0,027 \\
\hline \multirow{9}{*}{$\begin{array}{l}\text { Disability } \\
\text { scale }\end{array}$} & Difficulty walking at home & $4[3-5,2]$ & $2[0-2]$ & 0,002 \\
\hline & Difficulty walking outside & $6[4,7-7]$ & $2[1,5-2,5]$ & 0,019 \\
\hline & Difficulty walking $800 \mathrm{~m}$ & $6[3,7-7]$ & $2[1,5-2,5]$ & 0,003 \\
\hline & Difficulty climbing stairs & $5,5[3-7,2]$ & $3[1-5,2]$ & 0,032 \\
\hline & Difficulty descending stairs & $5,5[3-7,2]$ & $3[1-5,2]$ & 0,022 \\
\hline & Difficulty standing on tiptoe & $6,5[5-10]$ & $7[2,5-9,2]$ & 0,687 \\
\hline & Difficulty getting up from a chair & $5[4-6,2]$ & $3[3-5]$ & 0,032 \\
\hline & Difficulty climbing a sidewalk & $4[2-5,5]$ & $3[0-5]$ & 0,137 \\
\hline & Difficulty walking fast & $5[2,2-6]$ & $3,5[0-8]$ & 0,648 \\
\hline \multirow{5}{*}{$\begin{array}{l}\text { Activity } \\
\text { limitation }\end{array}$} & Stay all day at home & $2[1,5-5,2]$ & $0[0-2]$ & 0,077 \\
\hline & Stay all day lying down & $2[0-4]$ & $0[0-2]$ & 0,122 \\
\hline & Limitation of activities & $2[2-5]$ & $1[1-2,2]$ & 0,1 \\
\hline & Use of indoor walking aids & $0[0-0]$ & $0[0-0]$ & 1 \\
\hline & Use of walking aid outside & $0[0-0]$ & $0[0-0]$ & 0,18 \\
\hline \multicolumn{2}{|r|}{ Pain scale } & $37[32,5-47,5]$ & $36[24,5-40,5]$ & 0,198 \\
\hline \multicolumn{2}{|r|}{ Disability scale } & $49[34-59]$ & $27[13,2-46,2]$ & 0,011 \\
\hline \multicolumn{2}{|r|}{ Activity limitation } & $7[5,5-7]$ & $2,5[0-5,2]$ & 0,126 \\
\hline \multicolumn{2}{|r|}{ Total FFI score } & $95[82-106]$ & $65,5[37,5-87]$ & 0,024 \\
\hline
\end{tabular}

$p$ significatif if $<0,05$; Test used: Non-parametric test for two linked samples.

Conclusion: Foot orthoses were effective as an adjuvant in the management of rheumatoid foot. They significantly reduced disability as measured by the FFI. The absence of factors associated with pain and limitation of activity could possibly be related to the small sample size.

Disclosure of Interests: None declared

DOI: 10.1136/annrheumdis-2020-eular.6308

\section{FRI0613-HPR THE EFFECTS OF PILATES TRAINING ON RESPIRATORY MUSCLE STRENGHT IN PATIENTS WITH ANKYLOSING SPONDYLITIS}

S. Baglan Yentur ${ }^{1}$, D. C. Saraç ${ }^{2}$, F. Sari ${ }^{2}$, N. G. Tore ${ }^{2}$, H. Satış ${ }^{2}$, M. A. Ozturk², D. Oskay ${ }^{2} .{ }^{1}$ Fırat University, Elazığ, Turkey; ${ }^{2}$ Gazi Üniversity, Ankara, Turkey

Background: Ankylosing Spondylitis (AS) is a chronic, inflammatory rheumatic disease that effects primarily axial spine. Reduction in flexibility and mobility is important factors that can cause muscle weakness, impairment quality of life, reduction of exercise tolerance and pulmonary capacity with the progression of AS. Objectives: The purpose of this study was to investigate the effects of pilates exer cises on mobility, quality of life and respiratory muscle strength in patients with AS.

Methods: Forty patients with AS were randomly divided into two groups as pilates group and control group. Pilates group was performed pilates exercises and control group performed conventional exercises at home for 8 weeks, 3 days a week. Main outcome measures were maximal inspiratory pressure (MIP), maximal expiratory pressure (MEP). Secondary outcome measures were Forced Vital Capacity (FVC), Forced expiratory volume in one second/Forced Vital Capacity (FEV1/FVC), chest expansion, Bath Ankylosing Spondylitis Disease Activity Index (BASDAI), Bath Ankylosing Spondylitis Metrology Index (BASMI) and Ankylosing Spondylitis Quality of Life Questionnaire (ASQoL), 6 minutes walk test (6MWT). All participants were assessed by a blind assessor before and after the study. Results: Thirty-six AS patients $(n=19$ in the pilates group, $n=17$ in the control group) completed the study. In the pilates group, respiratory muscle strength FEV1/FVC, chest expansion, BASDAI, BASMI, ASQoL and 6MWT showed sig nificant improvements at $8^{\text {th }}$ week $(p<0.05)$, while inspiratory muscle strength FEV1/FVC, chest expansion and 6MWT showed significant improvements in the control group at $8^{\text {th }}$ week compared to baseline $(p<0.05)$. Although the pilates group had better outcomes for all parameters compared to the control group, significant differences were only observed in MIP and MEP.

Conclusion: Pilates method is an effective method for improving respiratory parameters, spinal mobility, disease activity and quality of life. Additionally, pilates training is found to be superior compared to conventional exercise training in improving respiratory muscle strength.

References:

[1] Sampaio-Barros PD, Cerqueira EMF, Rezende SM, Maeda L, Conde RA Zanardi VA et al. Pulmonary involvement in ankylosing spondylitis. Clinical rheumatology. 2007;26(2):225-30.

[2] Ozdem OY, Inanici F, Hascelik Z. Reduced vital capacity leads to exercise intolerance in patients with ankylosing spondylitis. European journal of physical and rehabilitation medicine. 2011;47(3):391-7.

[3] Altan L, Korkmaz N, Dizdar M, Yurtkuran M. Effect of Pilates training on people with ankylosing spondylitis. Rheumatology international. 2012;32(7):2093-9.

Disclosure of Interests: None declared

DOI: 10.1136/annrheumdis-2020-eular.2129

\section{FRI0614-HPR RECOMMENDATIONS FOR PATIENTS WITH RHEUMATIC DISEASES IN TREATMENT WITH METHOTREXATE}

I. Balaguer Trull ${ }^{1}$, V. Núñez-Monje ${ }^{2}$, I. Torner Hernández², A. Gómez Clari ${ }^{3}$ C. Cano ${ }^{4}$, I. Cánovas Olmos ${ }^{5}$, A. Carbonell Jordá ${ }^{6}$, J. De la Torre-Aboki ${ }^{7}$, M. D. Gil del Gallego ${ }^{8}$, E. Grau García ${ }^{5}$, M. Lorente Betoret ${ }^{4}$, E. Marín Martín ${ }^{9}$, N. Martinez Alberola $^{9}$, C. Nájera Herranz ${ }^{5}{ }^{7}$ Valencia General and University Hospital, Bone Metabolism and Rheumatology Unit, Valencia, Spain; ${ }^{2}$ Dr. Peset University Hospital, Rheumatology Unit, Valencia, Spain; ${ }^{3}$ Vinalopó University Hospital, Rheumatology Unit, Alicante, Spain; ${ }^{4}$ Marina Baixa Hospital, Rheumatology Unit, Alicante, Spain; ${ }^{5}$ La Fe University Hospital, Rheumatology Unit, Valencia, Spain; ${ }^{6}$ San Juan University Hospital, Rheumatology Unit, Alicante, Spain; ${ }^{7}$ Alicante General and University Hospital, Day Hospital, Alicante, Spain; ${ }^{8}$ Virgen de los Lirios Hospital, Rheumatology Unit, Alicante, Spain; ${ }^{9}$ Elda General and University Hospital, Rheumatology Unit, Alicante, Spain

Background: Methotrexate (MTX) is the first choice disease-modifying anti-rheumatic drug (FAME) in the treatment of rheumatoid arthritis among other rheumatic diseases. It is therefore very important that patients are aware of this treatment and have an adequate management of it.

Objectives: The development of a recommendation leaflet for patients with rheumatic diseases in treatment with MTX.

Methods: A systematic review of the literature was conducted, defining the criteria for inclusion and exclusion of content. The coordinators of the work generated preliminary recommendations that were evaluated and discussed in GESVR meetings and 10 recommendations on the use of MTX were accepted, which were later ratified by the Valencian Society of Rheumatology.

Results: The final document with a brief introduction indicates that MTX can be administered orally or subcutaneously, depending on the prescribed dose and its tolerance. In the case of subcutaneous administration, pre-filled syringes or pens are used which do not require any preparation, so there is no risk of handling and/ or inhalation toxicity. The proposed recommendations are described below:

[1] MTX should be taken or administered ONLY once a week, and always on the same day of the week. It is important to follow these recommendations to ensure adequate effectiveness and avoid side effects.

[2] It is common to add a folic acid supplement the day after MTX is taken to avoid certain side effects of the drug. In some cases it may be necessary to increase the dose to other days of the week. 